OPEN ACCESS

Edited by:

Olayinka Olabode Ogunleye, Lagos State University, Nigeria

Reviewed by:

Ronald Kiguba,

Makerere University, Uganda Prince Kasongo Mwila, Potchefstroom Hospital, South Africa

*Correspondence: Kotoji Iwamoto iwamotok@who.int

Specialty section: This article was submitted to Drugs Outcomes Research and

Policies,

a section of the journal Frontiers in Pharmacology

Received: 08 December 2020 Accepted: 19 March 2021 Published: 17 June 2021

Citation:

Robertson J, Vlahović-Palčevski V, Iwamoto K, Högberg LD, Godman B,

Monnet DL, Garner S, Weist $K$

ESAC-Net Study Group and WHO

Europe AMC Network Study Group (2021) Variations in the Consumption

of Antimicrobial Medicines in the

European Region, 2014-2018: Findings and Implications from ESAC-

Net and WHO Europe.

Front. Pharmacol. 12:639207.

doi: 10.3389/fphar.2021.639207

\section{Variations in the Consumption of Antimicrobial Medicines in the European Region, 2014-2018: Findings and Implications from ESAC-Net and WHO Europe}

\author{
Jane Robertson ${ }^{1,2}$, Vera Vlahović-Palčevski ${ }^{3}$, Kotoji Iwamoto ${ }^{1 *}$, Liselotte Diaz Högberg ${ }^{4}$, \\ Brian Godman ${ }^{5,6}$, Dominique L. Monnet ${ }^{4}$, Sarah Garner ${ }^{1}$, Klaus Weist ${ }^{4}$ \\ ESAC-Net Study Group and WHO Europe AMC Network Study Group

\begin{abstract}
${ }^{1}$ World Health Organization Regional Office for Europe, Copenhagen, Denmark, ${ }^{2}$ Department of Clinical Pharmacology, The University of Newcastle, Callaghan, NSW, Australia, ${ }^{3}$ Department of Clinical Pharmacology, University Hospital Rijeka/Medical Faculty and Faculty of Health Studies, University of Rijeka, Rijeka, Croatia, ${ }^{4}$ European Centre for Disease Prevention and Control, Solna, Sweden, ${ }^{5}$ Strathclyde Institute of Pharmacy and Biomedical Sciences, University of Strathclyde, Glasgow, United Kingdom, ${ }^{6}$ Department of Public Health Pharmacy and Management, School of Pharmacy, Sefako Makgatho Health Sciences University, Pretoria, South Africa
\end{abstract}

Background: Surveillance of antimicrobial consumption (AMC) is important to address inappropriate use. AMC data for countries in the European Union (EU) and European Economic Area (EEA) and Eastern European and Central Asian countries were compared to provide future guidance.

Methods: Analyses of 2014-2018 data from 30 EU/EEA countries of the European Surveillance of Antibiotic Consumption network (ESAC-Net) and 15 countries of the WHO Regional Office for Europe (WHO Europe) AMC Network were conducted using the Anatomical Therapeutic Chemical (ATC) classification and Defined Daily Dose (DDD) methodology. Total consumption (DDD per 1000 inhabitants per day) of antibacterials for systemic use (ATC group J01), relative use (percentages), trends over time, alignment with the WHO Access, Watch, Reserve (AWaRe) classification, concordance with the WHO global indicator (60\% of total consumption should be Access agents), and composition of the drug utilization $75 \%$ (DU75\%) were calculated.

Findings: In 2018, total consumption of antibacterials for systemic use (ATC J01) ranged from 8.9 to 34.1 DDD per 1000 inhabitants per day (population-weighted mean for ESACNet 20.0, WHO Europe AMC Network 19.6, ESAC-Net Study Group, and WHO Europe AMC Network Study Group). ESAC-Net countries consumed more penicillins (J01C; 8.7 versus 6.3 DDD per 1000 inhabitants per day), more tetracyclines (J01A; 2.2 versus 1.2), less cephalosporins (J01D; 2.3 versus 3.8) and less quinolones (J01M; 1.7 versus 3.4) than WHO Europe AMC Network countries. Between 2014 and 2018, there were statistically significant reductions in total consumption in eight ESAC-Net countries. In 2018, the relative population-weighted mean consumption of Access agents was 57.9\% for ESACNet and 47.4\% for the WHO Europe AMC Network. For each year during 2014-2018, 
14 ESAC-Net and one WHO Europe AMC Network countries met the WHO global monitoring target of $60 \%$ of total consumption being Access agents. DU75\% analyses showed differences in the choices of agents in the two networks.

Interpretation: Although total consumption of antibacterials for systemic use was similar in the two networks, the composition of agents varied substantially. The greater consumption of Watch group agents in WHO Europe AMC Network countries suggests opportunities for improved prescribing. Significant decreases in consumption in several ESAC-Net countries illustrate the value of sustained actions to address antimicrobial resistance.

\section{Keywords: antibiotic utilization, antimicrobial medicines consumption, AWaRe classification, cross-national comparative study, drug utilization $\mathbf{7 5 \%}$, European Surveillance of Antibiotic Consumption Network, Eastern Europe, Central Asia}

\section{INTRODUCTION}

Antimicrobial resistance (AMR) is one of the main public health threats worldwide. It is estimated that each year about 33,000 deaths are attributable to infections with antibiotic resistant bacteria in the European Union (EU)/European Economic Area (EEA) (Cassini et al., 2019) and 700,000 globally (O'Neill, 2016). The Organization for Economic Co-operation and Development (OECD) predicts that the costs associated with AMR could increase to US\$ 3.5 billion per year if not addressed (Hofer, 2019).

However, the problem of AMR calls for concerted efforts at the local, regional and national level as well as close international cooperation which is not always forthcoming (Laxminarayan et al., 2020). Ensuring prudent antimicrobial use is a key priority in an effective response to AMR, as antimicrobial use exerts ecological pressure on bacteria and contributes to the emergence and selection of resistant bacteria. The importance of surveillance of antibiotic consumption to identify potential overuse, underuse and inappropriate use is highlighted in the World Health Organization (WHO) Global Action Plan on AMR (World Health Organization, 2015), as well as the WHO European Strategic Action Plan on Antibiotic Resistance (World Health Organization Regional Office for Europe, 2011) and the European One Health Action Plan against AMR (European Commission, 2017).

There are two main networks in the WHO European Region that collate data on consumption of antimicrobial medicines. The European Surveillance of Antimicrobial Consumption Network (ESAC-Net) coordinated by the European Centre for Disease Prevention and Control (ECDC) collates and analyses data on antibiotic consumption from 30 countries in the EU/EEA (European Centre for Disease Prevention and Control, 2020). Data are available since 1997 and are published on-line and in annual reports. The WHO Regional Office for Europe (WHO Europe) Antimicrobial Medicines Consumption (AMC) Network has been undertaking systematic surveillance of antimicrobial medicines consumption since 2011 (World Health Organization Regional Office for Europe, 2020a). AMC data for 2011-2017 for
17 network members have been published (World Health Organization Regional Office for Europe, 2020b).

Both networks use standardized methods to collect and analyze data for total AMC, and where possible, disaggregated to community and hospital AMC. Data collection is based on the WHO Anatomical Therapeutic Chemical (ATC) classification system and Defined Daily Dose (DDD) methodology (WHO ATC/DDD Index, 2018, 2020). Few data have been published comparing AMC data from the two networks. Data on total antibiotic consumption in 2011 and 2015 have been published (Versporten et al., 2014; Robertson et al., 2019). The WHO global report on antimicrobial consumption presented combined European data for 2015 (World Health Organization, 2018).

This study extends these comparisons, comparing data from 30 EU/EEA countries participating in ESAC-Net with data from 15 countries of the WHO Europe AMC Network where Ministries of Health have agreed on data sharing and publication. The aim of this study was to examine total consumption and patterns of consumption of antibiotics, i.e. antibacterials for systemic use (ATC group J01), in DDD per 1000 inhabitants per day. This is the primary indicator of antibiotic consumption in countries as defined by the European Commission and WHO (European Centre for Disease Prevention and Control, European Food Safety Authority and European Medicines Agency (ECDC/EFSA/ EMA), 2017a). The relative consumption of oral and parenteral formulations, the comparative use of WHO Access, Watch and Reserve (AWaRe) antibiotics, and concordance with the monitoring indicator that $60 \%$ of total consumption should be Access agents (Sharland et al., 2019; Klein et al., 2020; World Health Organization, 2020) were assessed and trends over time examined. In the absence of indication-linked information on antibiotic use, the WHO AWaRe classification allows a more detailed analysis of aggregated data and opportunities for stewardship activities (Sharland et al., 2019). The AWaRe classification has been applied to patterns of total antibiotic consumption globally in 2015 (World Health Organization, 2018), changes over time between 2000 and 2015 (Klein et al., 2020), analyses of pediatric antibiotic sales data (Hsia et al., 2019a), published 


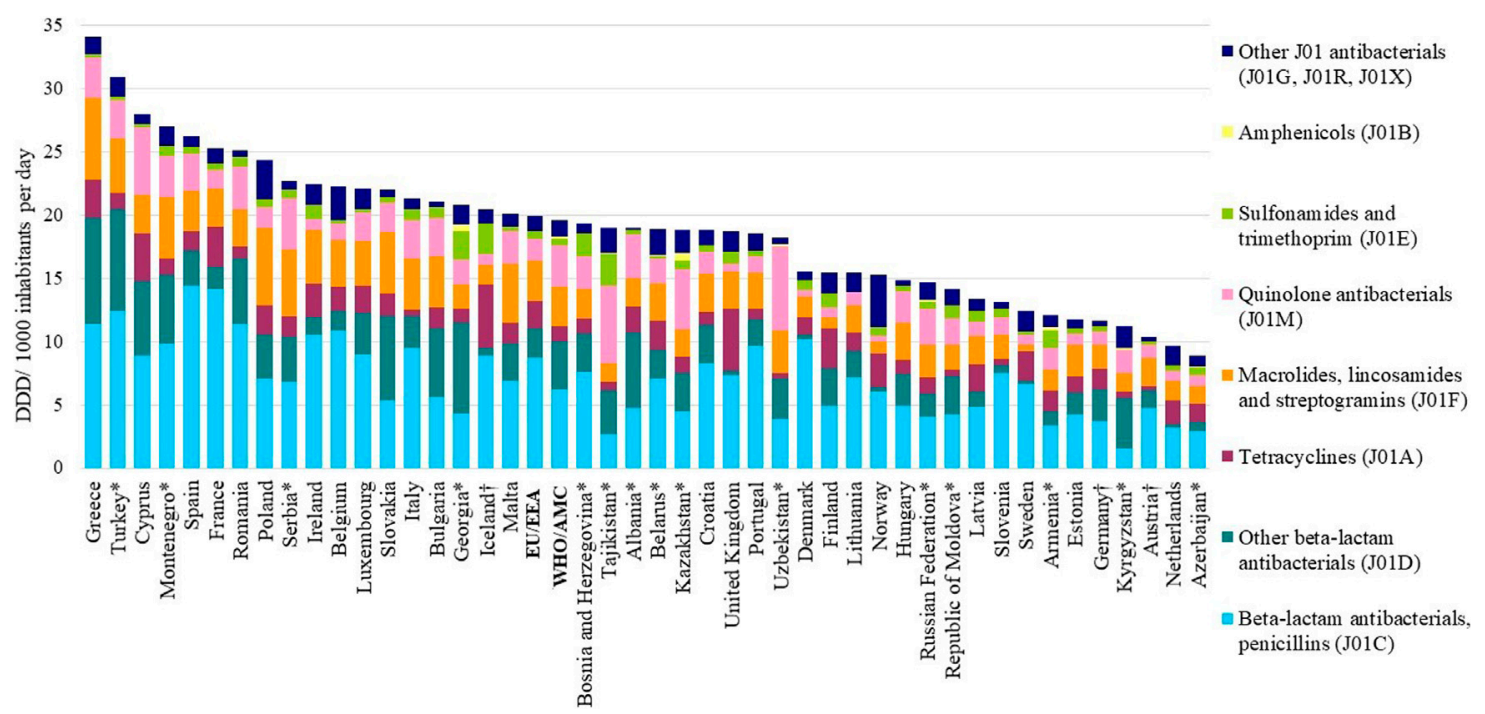

FIGURE 1 | Total consumption of antibacterials for systemic use (ATC J01) expressed in DDD per 1000 inhabitants per day, by pharmacological subgroup, 2018. *Member of the WHO Europe AMC Network. EU/EEA: population-weighted mean for countries of ESAC-Net. WHO/AMC: population-weighted mean for countries of the WHO Europe AMC Network. ${ }^{\dagger}$ Countries reported only community data.

studies of antibiotic use in low- and middle-income countries (Sulis et al., 2020), analyses of national consumption estimates (McGettigan et al., 2017; Malik and Figueras, 2019; Public Health Agency of Canada, 2020) and patterns of consumption in hospitals (Schweickert et al., 2018; Hsia et al., 2019b).

The combined data presented here provide a pan-European perspective on rates and patterns of AMC between 2014 and 2018.

\section{MATERIALS AND METHODS}

\section{Data Collection}

The data for this study were retrieved from two surveillance networks in Europe - 30 countries of the ESAC-Net and 15 countries of the WHO Europe AMC Network - for the period 2014 to 2018 (data last reviewed on October 1, 2020; Figure 1). Details on the methods of data collection and analysis for both networks have previously been published (European Centre for Disease Prevention and Control, 2020; World Health Organization Regional Office for Europe, 2020b). Briefly, data collection follows standardized protocols and only includes medicines with an assigned ATC code, facilitating analyses from the main classes (ATC level 1) to individual substances (ATC level 5). The main analyses presented here are for the antibacterials for systemic use (ATC group J01). Data on additional antimicrobials are included in the calculation of the WHO Access, Watch and Reserve (AWaRe) classification (World Health Organization, 2019), namely neomycin (A07AA01), streptomycin (A07AA04), polymyxin B (A07AA05), kanamycin (A07AA08), vancomycin (A07AA09), colistin (A07AA10), rifamixin (A07AA11), rifampicin (J04AB02), rifamycin (J04AB03), rifabutin (J04AB04), metronidazole (P01AB01).

\section{Data Sources}

ESAC-Net data are predominantly derived from sales data, reimbursement data or a combination of these sources (Supplementary Table S1A). Reimbursement data do not include consumption of antimicrobials obtained without prescription and other non-reimbursed courses of therapy compared to sales data. The extent of consumption not included when using only reimbursement data may vary by country (Safrany and Monnet, 2012). ESAC-Net data represent total coverage of consumption in the countries except for Germany (85\% coverage), the Netherlands (92\%) and Luxembourg (91\%).

Countries that participate in the WHO Europe AMC Network mostly rely on import data using customs records and declaration forms supplemented with sales records from market authorization holders, local manufacturing estimates, wholesaler records, and in some cases, commercial data sources (Supplementary Table S1B). Data represent total consumption estimates except for Kazakhstan where a commercial data source provides coverage of $80 \%$ of hospital and community sales.

Across both networks, there are countries that have changed data sources during the study period and/or where data are not available for all years examined.

\section{Data Analysis and Metrics Reported}

Data disaggregated to community and hospital sector consumption were not available for all studied countries. Consequently, the main analyses presented here are for total consumption across both sectors combined. Total numbers of DDDs for each product were aggregated to give the total number of DDDs at the desired ATC code level and adjusted for the population size to calculate DDDs per 1000 inhabitants per day. For countries where there was incomplete coverage, data were extrapolated to estimate $100 \%$ consumption to facilitate comparisons across countries and networks. The ATC/DDD 
Index 2019 was applied to all years of data to facilitate analysis of trends over time (WHO Collaborating Centre for Drug Statistics Methodology, 2020). Eurostat (European Commission 2020a) or national population estimates were used for EU/EEA countries and World Bank population estimates (The World Bank, 2020) were applied to WHO Europe AMC Network countries apart from Turkey, where estimates were adjusted to take account of the large refugee population. Patterns of consumption of antibacterials for systemic use (ATC group J01) by ATC level 3 sub-groups and by route of administration (oral and parenteral) in 2018 were assessed.

Measures of relative consumption, expressed as a percentage of total consumption of groups of antimicrobials, were derived for 3rd ATC level group of antibacterials for systemic use, and for the WHO AWaRe groups of antibiotics (World Health Organization, 2019). The proportion of total consumption that comprised Access agents was calculated and trends 2014-2018 assessed.

The most frequently used antibiotic substances comprising $75 \%$ of the total consumption (the Drug Utilization 75\%, DU75\%) were derived and stratified by route of administration (Zarb et al., 2011).

Summary data were considered for the networks separately using arithmetic and population-weighted mean estimates. For each network, a population-weighted estimate of total consumption was calculated by multiplying DDD per 1000 inhabitants per day for each country with the corresponding population, then summing the country estimates and finally dividing the resulting total number of DDDs by the total population of all participating countries (European Centre for Disease Prevention and Control, 2019a). Using similar methods, population-weighted estimates were calculated for the relative consumption of AWaRe groups of antibiotics and for components of the DU75\%.

Simple linear regression was used to assess trends in antibiotic consumption for each participating country. The output of the software used (Excel data analysis module) includes the regression statistics of a linear regression analysis and the corresponding analysis of variance (ANOVA) test statistics. To illustrate changes in antimicrobial consumption rates over time, we calculated the compound annual growth rate (CAGR) of total antibiotic consumption for each country, which reflects the average annual change as a proportion (\%) of the consumption in the starting year. CAGR were estimated for countries that had five years of available data. $\mathrm{P}$ values $\leq 0.05$ were considered statistically significant.

\section{Role of the Funding Source}

For ESAC-Net, no specific funding was allocated for this study. Netherlands Ministry of Health, Welfare, and Sport, and the German Collaboration Program provide funding for the WHO Europe AMC Network, but had no role in the study design, data collection, data analysis, data interpretation, or writing of the manuscript.

\section{RESULTS}

The arithmetic mean and the population-weighted mean total consumption of antibacterials for systemic use (ATC group J01) in 2018 were similar in the two networks-19.0 and 20.0 DDD per
1000 inhabitants per day, respectively, for ESAC-Net compared to 18.4 and 19.6 DDD per 1000 inhabitants per day, respectively, for the WHO Europe AMC Network. However, large inter-country variations were seen among both the 29 ESAC-Net countries (9.7-34.1 DDD per 1000 inhabitants per day) and the $15 \mathrm{WHO}$ Europe AMC Network countries (8.9-30.9 DDD per 1000 inhabitants per day) (Figures 1, 2, Supplementary Table S2).

In 2018, the relative consumption of parenteral formulations varied within and between networks. For the 26 ESAC-Net countries for which hospital sector data were included in total consumption of antibacterials for systemic use, parenteral formulations represented from 3.6 to $23.9 \%$ of total consumption (median 5.9\%). For the 15 WHO Europe AMC Network countries, parenteral formulations comprised between 2.8 and $40.1 \%$ (median 13.1\%) of total consumption (Supplementary Table S3).

The population-weighted consumption of penicillins (ATC J01C) differed in the two networks - 8.7 versus 6.3 DDD per 1000 inhabitants per day and representing 43.8 and $31.9 \%$ of total consumption of antibacterials for systemic use for ESAC-Net and WHO Europe AMC Network countries, respectively (Supplementary Table S2). Penicillins were the most consumed subgroup of antibiotics in 28 (97\%) of 29 ESAC-Net countries (range $24.3-65.9 \%$ of total consumption) and 9 (67\%) of $15 \mathrm{WHO}$ Europe AMC Network countries (range 14.2-40.2\%).

In ESAC-Net countries, there was more consumption of tetracyclines (J01A; population-consumption 2.2 versus $1.2 \mathrm{DDD}$ per 1000 inhabitants per day), less consumption of other betalactams, predominantly cephalosporins (J01D; 2.3 versus 3.8 DDD per 1000 inhabitants per day), and less consumption of quinolone antibiotics (J01M; 1.7 versus 3.4 DDD per 1000 inhabitants per day) than in WHO Europe AMC Network countries (Supplementary Table S2). There was no or very little reported consumption of amphenicols (J01B) in ESAC-Net countries and low levels of consumption in only three countries of the WHO Europe AMC Network: Armenia (0.3 DDD per 1000 inhabitants per day, 2.2\% total consumption), Kazakhstan (0.6 DDD per 1000 inhabitants per day, 3.1\%) and Georgia (0.6 DDD per 1000 inhabitants per day, 2.7\%).

\section{Trends, 2014-2018}

Table 1 shows the trends in total consumption of antibacterials for systemic use (ATC group J01) for the years 2014-2018. There were statistically significant increases in total consumption over the study period in Greece (2.4\%) and Iceland (4.5\%). Statistically significant decreases in total consumption over the study period were reported in Denmark (CAGR $-2.5 \%)$, Finland $(-5.2 \%)$, Germany (-3.4\%), Luxembourg (-1.3\%), Netherlands $(-1.5 \%)$, Norway $(-2.5 \%)$, Sweden $(-2.9 \%)$ and the United Kingdom $(-2.6 \%)$. Only one country among the WHO Europe AMC Network countries had a statistically significant increase or decrease in total consumption over the study period, namely Bosnia and Herzegovina (+6.0\%).

\section{WHO AWaRe Classification Medicines}

The relative consumption of AWaRe antibiotics in 2018 is shown for the two networks separately in Figure 3, and summarized in Supplementary Tables S4A and S4B. Access antibiotics 


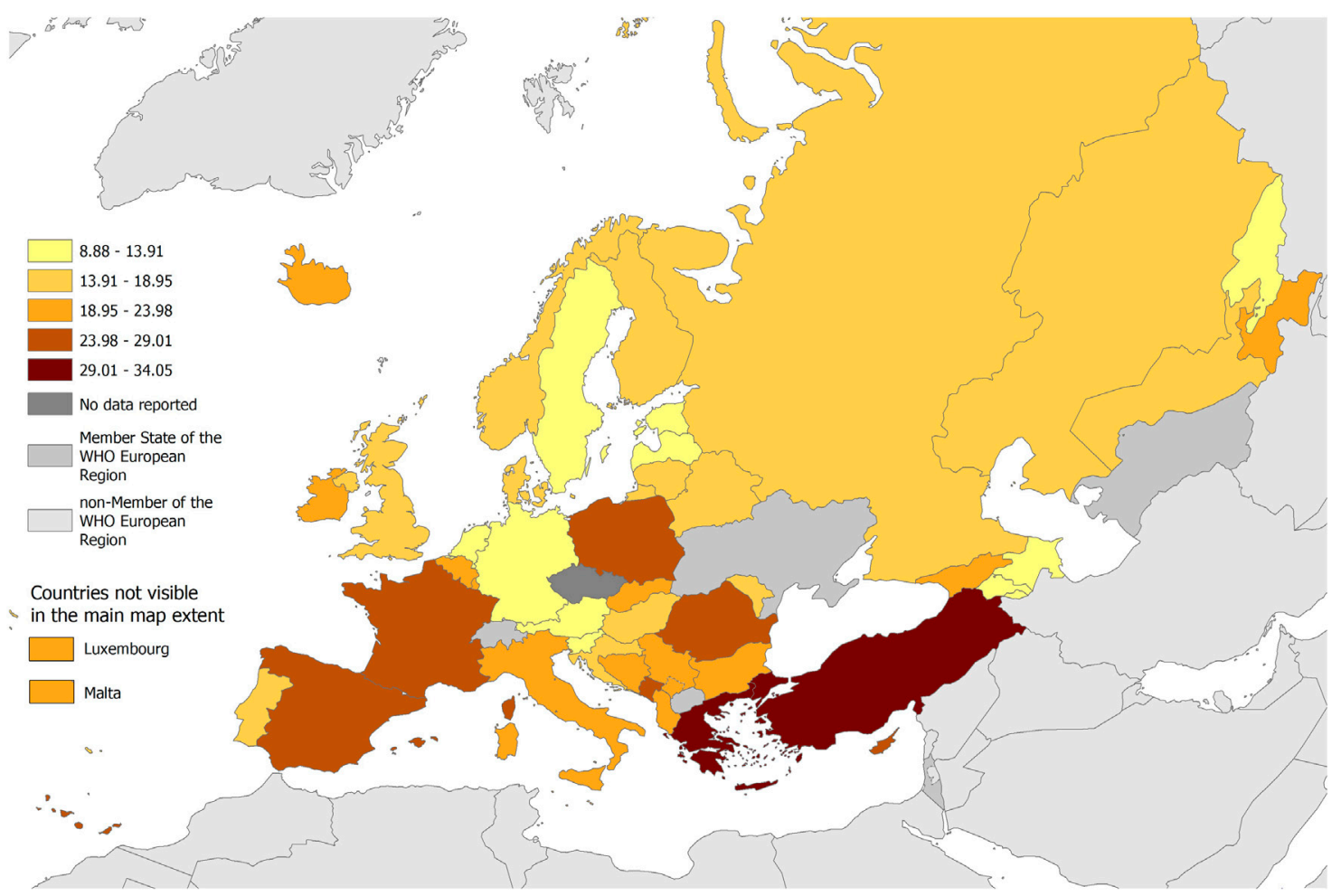

Data Source: ECDC and WHO Regional office for Europe. Administrative boundaries: (๑) EuroGeographics (๑) UN-FAO (๑) Turkstat. The boundaries and names shown on this map do not imply official endorsement or acceptance by the European Union. Map produced on: 13 Nov 2020. Scale: 1:28,500,000.

FIGURE 2 | Total consumption of antibacterials for systemic use (ATC J01) (expressed as DDD per 1000 inhabitants per day) for countries of ESAC-Net and the WHO/Euro AMC Network, 2018. Austria, Iceland and Germany reported only community data.

comprised more than $60 \%$ of total consumption in 17 (59\%) of 29 ESAC-Net countries and three (20\%) of 15 WHO Europe AMC Network countries that provided 2018 data. The populationweighted mean consumption of Access agents was $57.9 \%$ for ESAC-Net and $47.4 \%$ for the WHO Europe AMC Network.

The relative consumption of Watch antibiotics ranged from $13 \%$ (Iceland) to $61 \%$ (Slovakia) of total consumption for ESACNet countries and from 34\% (Bosnia and Herzegovina) to $69 \%$ (Uzbekistan) of total consumption for WHO Europe AMC Network countries.

Reserve antibiotics represented $<1 \%$ of total consumption in all countries included in this analysis. The extent of consumption of unclassified agents varied and was the highest in Norway and Poland, representing 24 and $12 \%$ of total consumption, respectively.

Trends in the relative consumption of AWaRe agents between 2014 and 2018 are shown in Table 2. According to the WHO global indicator, i.e. $60 \%$ of total consumption should be of Access agents, 14 (48\%) of 29 ESAC-Net countries achieved this target in each of the five years examined. Only one country in the WHO Europe AMC Network met this target in all five years.

\section{Drug Utilization $\mathbf{7 5 \%}$}

Table 3 (oral agents) and Table 4 (parenteral agents) show the agents that comprise $75 \%$ of total consumption of antibacterials agents for systemic use (ATC group J01) in each of the participating countries and networks separately and summarized across each of the networks.
The number of agents constituting the DU75\% for oral substances ranged from 5-9 (median 7) for ESAC-Net countries and 4-10 (median 8) for the WHO Europe AMC Network countries (Table 3). Across all countries in the network combined, the DU75\% comprised 10 agents each for ESAC-Net and the WHO Europe AMC Network.

Oral amoxicillin with enzyme inhibitor (ATC code J01CR02) was the most consumed oral agent across both networks and ranked number one in 15 (52\%) of 29 ESAC-Net countries and in five $(33 \%)$ of 15 WHO Europe AMC Network countries. Oral amoxicillin alone (J01CA04) was ranked number two overall across both networks and ranked number one in six (21\%) ESAC-Net countries and six (40\%) of WHO Europe AMC Network countries.

However, there were substantial variations in the distribution of antibiotics. Three agents, phenoxymethylpenicillin (J01CE02), flucloxacillin (J01CF05) and pivmecillinam (J01CA08) were not included in the DU75\% of any of the 15 WHO Europe AMC Network countries. phenoxymethylpenicillin ranked first in Denmark and Sweden, and second in Norway. Pivmecillinam ranked second in Denmark, fourth in Norway and sixth in Iceland.

Notably, Watch group agents were included in the DU75\% for all countries. Across all network countries combined, Watch group agents represented four of nine agents in the DU75\% for ESAC-Net and five of ten agents in the DU75\% for the WHO Europe AMC Network. 
TABLE 1 | Trends in total consumption of antibacterials for systemic use (ATC J01), 2014-2018.

\begin{tabular}{|c|c|c|c|c|c|c|c|c|}
\hline \multirow[t]{2}{*}{ Country } & \multicolumn{5}{|c|}{ DDD per 1000 inhabitants per day } & & \multirow[t]{2}{*}{ CAGR $^{\#}$} & \multirow[t]{2}{*}{ Trend } \\
\hline & 2014 & 2015 & 2016 & 2017 & 2018 & & & \\
\hline Albania* & 19.6 & 16.3 & 16.5 & 18.7 & 19.0 & & -0.7 & \\
\hline Armenia* & 12.7 & 9.4 & 9.4 & 12.0 & 12.1 & & -1.3 & \\
\hline Austria & 12.1 & 12.1 & 11.4 & 11.9 & 10.3 & & -3.8 & \\
\hline Azerbaijan* & 6.4 & 7.4 & 9.5 & 7.8 & 8.9 & $\underset{\longrightarrow}{\longrightarrow}$ & 8.5 & \\
\hline Belarus* & 18.3 & 17.1 & 16.9 & 20.0 & 18.9 & $\longrightarrow$ & 0.8 & \\
\hline Belgium & 24.0 & 24.4 & 24.2 & 22.8 & 22.3 & & -1.8 & \\
\hline Bosnia and Herzegovina* & 15.3 & 16.3 & 18.0 & 17.4 & 19.3 & $\longrightarrow$ & 6.0 & $\uparrow$ \\
\hline Bulgaria & 20.0 & 20.1 & 19.2 & 20.5 & 21.1 & $\longrightarrow$ & 1.4 & \\
\hline Croatia & 19.4 & 19.7 & 18.7 & 18.6 & 18.8 & $\underset{.}{\longrightarrow}$ & -0.8 & \\
\hline Cyprus & 22.2 & 26.6 & 28.4 & 28.9 & 28.0 & $\rightleftarrows$ & 6.0 & \\
\hline Czechia & 17.1 & 17.4 & & & & & & \\
\hline Denmark & 17.1 & 17.5 & 17.0 & 16.2 & 15.5 & 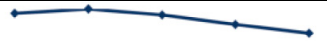 & -2.5 & $\downarrow$ \\
\hline Estonia & 11.9 & 12.1 & 12.0 & 11.6 & 11.8 & $\longrightarrow$ & -0.3 & \\
\hline Finland & 19.1 & 18.1 & 17.4 & 15.7 & 15.4 & $\underset{.}{\longrightarrow}$ & -5.2 & $\downarrow$ \\
\hline France & 24.9 & 25.6 & 25.6 & 24.7 & 25.3 & m & 0.4 & \\
\hline Georgia* & 17.9 & 24.2 & 22.5 & 25.1 & 20.8 & 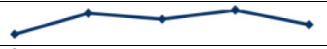 & 3.8 & \\
\hline Germany & 13.4 & 13.1 & 12.8 & 12.3 & 11.7 & $\underset{ }{\longrightarrow}$ & -3.4 & $\downarrow$ \\
\hline Greece & 31.0 & 33.2 & 33.1 & 34.2 & 34.1 & $\vec{\longrightarrow}$ & 2.4 & $\uparrow$ \\
\hline Hungary & 15.2 & 15.8 & 14.4 & 14.6 & 14.8 & $\longrightarrow$ & -0.5 & \\
\hline Iceland & 17.1 & 17.6 & 18.2 & 18.8 & 20.4 & $\longrightarrow$ & 4.5 & $\uparrow$ \\
\hline Ireland & 21.0 & 23.0 & 22.0 & 20.9 & 22.4 & $\longrightarrow$ & 1.7 & \\
\hline Italy & 24.5 & 24.5 & 24.0 & 20.9 & 21.4 & $\longrightarrow$ & -3.4 & \\
\hline Kazakhstan* & & 21.8 & 19.7 & 17.9 & 18.8 & $\longrightarrow$ & & \\
\hline Kyrgyzstan* & & 16.7 & 21.3 & 16.9 & 11.2 & 7 & & \\
\hline Latvia & 12.6 & 13.1 & 12.9 & 13.9 & 13.4 & $\longrightarrow$ & 1.6 & \\
\hline Lithuania & 15.1 & 15.8 & 15.6 & 15.7 & 15.4 & $=$ & 0.6 & \\
\hline Luxembourg & 23.2 & 23.5 & 22.9 & 22.6 & 22.1 & $\rightarrow$ & -1.3 & $\downarrow$ \\
\hline Malta & 22.4 & 21.2 & 20.9 & 22.6 & 20.2 & $\rightarrow>$ & -2.6 & \\
\hline Montenegro* & 26.7 & 29.0 & 28.9 & 27.1 & 27.0 & $\longrightarrow$ & 0.3 & \\
\hline Netherlands & 10.3 & 10.4 & 10.1 & 9.8 & 9.7 & $\longrightarrow$ & -1.5 & $\downarrow$ \\
\hline Norway & 16.9 & 16.8 & 16.2 & 15.7 & 15.3 & $\longrightarrow$ & -2.5 & $\downarrow$ \\
\hline Poland & 21.2 & 24.1 & 22.0 & 25.4 & 24.4 & $\longrightarrow$ & 3.6 & \\
\hline Portugal & 18.0 & 18.8 & 19.0 & 17.8 & 18.6 & $\gamma^{2}$ & 0.7 & \\
\hline Republic of Moldova* & 16.7 & 12.9 & 16.7 & 17.1 & 14.2 & $=$ & -4.1 & \\
\hline Romania & 26.6 & 28.0 & 24.4 & 24.5 & 25.1 & $\longrightarrow$ & -1.5 & \\
\hline Russian Federation* & 13.4 & 14.1 & 14.9 & 15.1 & 14.7 & $\longrightarrow$ & 2.3 & \\
\hline Serbia* & 25.3 & 31.0 & 26.2 & 21.3 & 22.7 & $\longrightarrow$ & -2.6 & \\
\hline Slovakia & 21.2 & 24.2 & 23.6 & 20.0 & 22.0 & $\gamma^{2}$ & 0.9 & \\
\hline Slovenia & 13.1 & 13.3 & 12.1 & 12.2 & 13.2 & $\longrightarrow$ & 0.2 & \\
\hline Spain $^{8}$ & 17.1 & 17.5 & 27.5 & 26.8 & 26.2 & & 11.3 & \\
\hline Sweden & 14.0 & 13.5 & 13.2 & 12.8 & 12.4 & $\longrightarrow$ & -2.9 & $\downarrow$ \\
\hline Tajikistan* & 31.0 & 21.7 & 20.9 & 16.3 & 19.0 & $\longrightarrow$ & -11.5 & \\
\hline Turkey* & 34.7 & 35.5 & 35.3 & 31.0 & 30.9 & $\longrightarrow$ & -2.9 & \\
\hline United Kingdom & 20.8 & 20.1 & 19.7 & 19.3 & 18.7 & $\longrightarrow$ & -2.6 & $\downarrow$ \\
\hline Uzbekistan* & & & 25.1 & 16.3 & 18.2 & $\longrightarrow$ & & \\
\hline
\end{tabular}

*member of the WHO Europe AMC Network.

\#CAGR: compound average growth rate. The CAGR was only calculated where there was five years of data (2014-2018) available for the country.

slinear regression not applied due to changes in data sources and/or sectors for which data were reported.

$\uparrow \downarrow$ arrows indicate statistically significant change. 


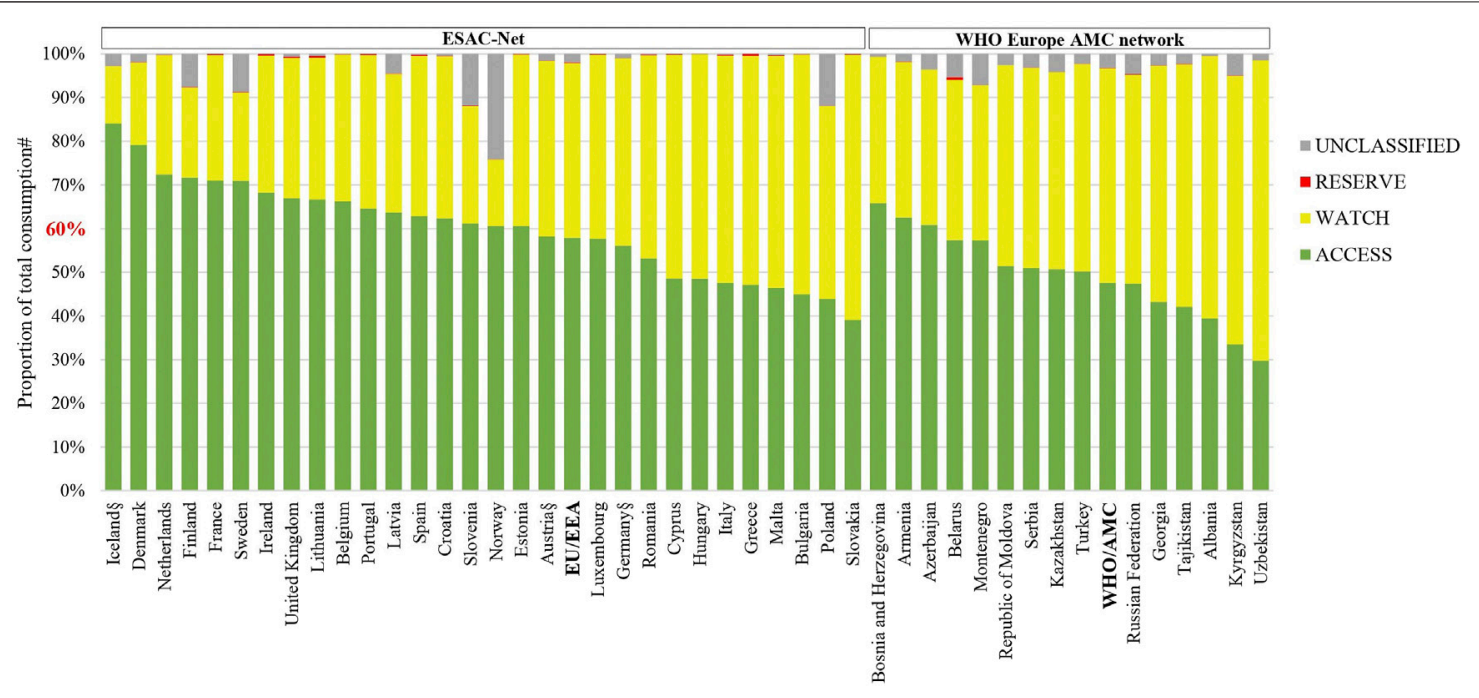

FIGURE 3 | Patterns of consumption of antibacterials according to the AWaRe classification of antimicrobial agents, 2018. AWaRe: Access, Watch and Reserve classification of antimicrobials (World Health Organization 2019).

EU/EEA: population-weighted mean for countries of ESAC-Net.

WHO/AMC: population-weighted mean for countries of the WHO Europe AMC Network.

${ }^{\#}$ Agents included in this analysis: antibacterials for systemic use (J01), neomycin (A07AA01), streptomycin 461 (A07AA04), polymyxin B (A07AA05), kanamycin (A07AA08), vancomycin (A07AA09), colistin 462 (A07AA10), rifamixin (A07AA11), rifampicin (J04AB02), rifamycin (J04AB03), rifabutin (J04AB04), 463 metronidazole (P01AB01).

${ }^{\S}$ Countries for which hospital sector data were not included.

Across all countries, the Watch group agents azithromycin (ATC code J01FA10), clarithromycin (J01FA09) and ciprofloxacin (J01MA02) were included in the DU75\% for 30, 25 and 25 countries, respectively. However, the relative rankings of these agents varied depending on the network. In ESAC-Net, clarithromycin ranked second for consumption in six (21\%) of 29 countries, third in a further four ESAC-Net countries and fourth in population-weighted estimates. Ciprofloxacin was ranked number one as most often consumed oral antibacterial in 3 (20\%) of $15 \mathrm{WHO}$ Europe AMC Network countries, second in another country, and third in population-weighted estimates. This agent ranked no higher than fourth in any ESAC-Net country. A second quinolone, levofloxacin (J01MA12), was the most often consumed oral antibacterial in one country of the WHO Europe AMC Network, although only ranked seventh in population-weighted estimates.

While parenteral agents represented between 2.8 and $40.1 \%$ of total consumption in 2018, there were 13 different parenteral agents included in the DU75\% for ESAC-Net and five agents for the WHO Europe AMC Network. Ceftriaxone (J01DD04), a Watch group agent, ranked as the most often consumed parenteral agent in $13(87 \%)$ of 15 WHO Europe AMC Network countries and 7 (24\%) of 29 ESAC-Net countries.

\section{DISCUSSION}

In 2018, total consumption of antibacterials for systemic use (ATC group J01) ranged from 8.9 for Azerbaijan to 34.1 DDD per 1000 inhabitants per day for Greece, with similar ranges of estimates for ESAC-Net and the WHO Europe AMC Network and similar estimates for the population-weighted mean total consumption (19.6 and 20.0 DDD per 1000 inhabitants per day, respectively). However, there were considerable differences in the absolute and relative consumption of 3rd ATC level groups, with greater consumption of penicillins and tetracyclines, and less consumption of cephalosporins and quinolones in ESAC-Net than in WHO Europe AMC Network countries.

During 2014-2018, there were statistically significant decreases in total consumption of antibacterials for systemic use (ATC J01) in eight ESAC-Net countries: Denmark, Finland, Germany, Luxembourg, the Netherlands, Norway, Sweden and the United Kingdom. These countries all have longstanding programmes and commitments toward reducing antibiotic consumption. WHO Europe AMC Network data were characterized by more inconsistent patterns, with only one country showing a significant trend for increased consumption over 2014-2018. This may reflect the nature of the data collection, often relying on customs records and data from local manufacturers as a crude proxy for consumption in these countries, as well as shorter histories of interventions to tackle AMR. The latter is, however, starting to change among some of the WHO Europe AMC Network countries (Robertson et al., 2019) and may be reflected in future trend analyses.

The observation of similar estimates of total consumption rates in conjunction with substantially different patterns of AMC suggests that relying on indicators measuring total consumption alone is inadequate to assess national performance. More detailed analyses at the formulation, group and individual agent level are needed to identify useful targets for national interventions to improve the use of antibiotics and promote alignment of clinical practices with international guidance on their responsible use. This is particularly important if patterns of 
TABLE 2 | Countries achieving the target of 60\% of total consumption of antibacterials being Access group agents, $2014-2018$.

\begin{tabular}{|c|c|c|c|c|c|}
\hline \multirow[t]{2}{*}{ Country } & \multicolumn{5}{|c|}{$\begin{array}{c}\text { Access agents as proportion (\%) of } \\
\text { total consumption }\end{array}$} \\
\hline & 2014 & 2015 & 2016 & 2017 & 2018 \\
\hline \multicolumn{6}{|l|}{ ESAC-Net } \\
\hline Austria & 57 & 57 & 58 & 58 & 58 \\
\hline Belgium & 57 & 57 & 58 & 61 & 66 \\
\hline Bulgaria & 49 & 46 & 44 & 45 & 45 \\
\hline Croatia & 61 & 63 & 65 & 63 & 62 \\
\hline Cyprus & 55 & 52 & 48 & 49 & 49 \\
\hline Czechia & 61 & 60 & & & \\
\hline Denmark & 78 & 79 & 79 & 79 & 79 \\
\hline Estonia & 59 & 58 & 60 & 59 & 61 \\
\hline Finland & 71 & 72 & 72 & 73 & 72 \\
\hline France & 66 & 68 & 70 & 71 & 71 \\
\hline Germany & 52 & 51 & 52 & 54 & 56 \\
\hline Greece & 40 & 44 & 48 & 46 & 47 \\
\hline Hungary & 49 & 48 & 48 & 48 & 49 \\
\hline Iceland & 84 & 83 & 82 & 83 & 84 \\
\hline Ireland & 62 & 66 & 65 & 65 & 68 \\
\hline Italy & 46 & 47 & 48 & 48 & 48 \\
\hline Latvia & 69 & 68 & 68 & 65 & 64 \\
\hline Lithuania & 70 & 70 & 69 & 68 & 67 \\
\hline Luxembourg & 53 & 54 & 53 & 47 & 58 \\
\hline Malta & 43 & 43 & 46 & 49 & 46 \\
\hline Netherlands & 71 & 72 & 71 & 71 & 72 \\
\hline Norway & 63 & 63 & 62 & 61 & 61 \\
\hline Poland & 64 & 63 & 61 & 59 & 44 \\
\hline Portugal & 60 & 59 & 60 & 64 & 65 \\
\hline Romania & 56 & 58 & 56 & 54 & 53 \\
\hline Slovakia & 47 & 43 & 46 & 42 & 39 \\
\hline Slovenia & 60 & 63 & 63 & 61 & 61 \\
\hline Spain & 63 & 63 & 63 & 63 & 63 \\
\hline Sweden & 71 & 70 & 71 & 71 & 71 \\
\hline United Kingdom & 65 & 65 & 66 & 66 & 67 \\
\hline \multicolumn{6}{|c|}{ WHO Europe AMC network } \\
\hline Albania & 61 & 48 & 51 & 44 & 39 \\
\hline Armenia & 66 & 66 & 57 & 66 & 63 \\
\hline Azerbaijan & 54 & 59 & 49 & 55 & 61 \\
\hline Belarus & 55 & 57 & 53 & 59 & 57 \\
\hline Bosnia and Herzegovina & 69 & 69 & 70 & 68 & 66 \\
\hline Georgia & 32 & 46 & 60 & 63 & 43 \\
\hline Kazakhstan & & 61 & 58 & 54 & 51 \\
\hline Kyrgyzstan & & 72 & 56 & 50 & 33 \\
\hline Montenegro & 61 & 56 & 58 & 59 & 57 \\
\hline Republic of Moldova & 46 & 52 & 43 & 46 & 51 \\
\hline Russian Federation & 49 & 48 & 49 & 49 & 47 \\
\hline Serbia & 68 & 64 & 63 & 60 & 51 \\
\hline Tajikistan & 65 & 58 & 61 & 46 & 42 \\
\hline Turkey & 44 & 45 & 46 & 47 & 50 \\
\hline Uzbekistan & & & 31 & 42 & 30 \\
\hline
\end{tabular}

${ }^{a}$ Agents included in this analysis: antibacterials for systemic use (J01), neomycin (A07AA01), streptomycin (A07AA04), polymyxin B (A07AA05), kanamycin (A07AA08), vancomycin (A07AA09), colistin (A07AA10), rifamixin (A07AA11), rifampicin (J04AB02), rifamycin (J04AB03), rifabutin (J04AB04), metronidazole (P01AB01).

Country estimates are rounded up.

Green panel identifies countries meeting the WHO global indicator that Access agents should constitute 60\% of total antibacterial consumption. 
TABLE 3 | Antibacterials at substance level (5th ATC group level) that compose the DU75\%, oral use, 2018.

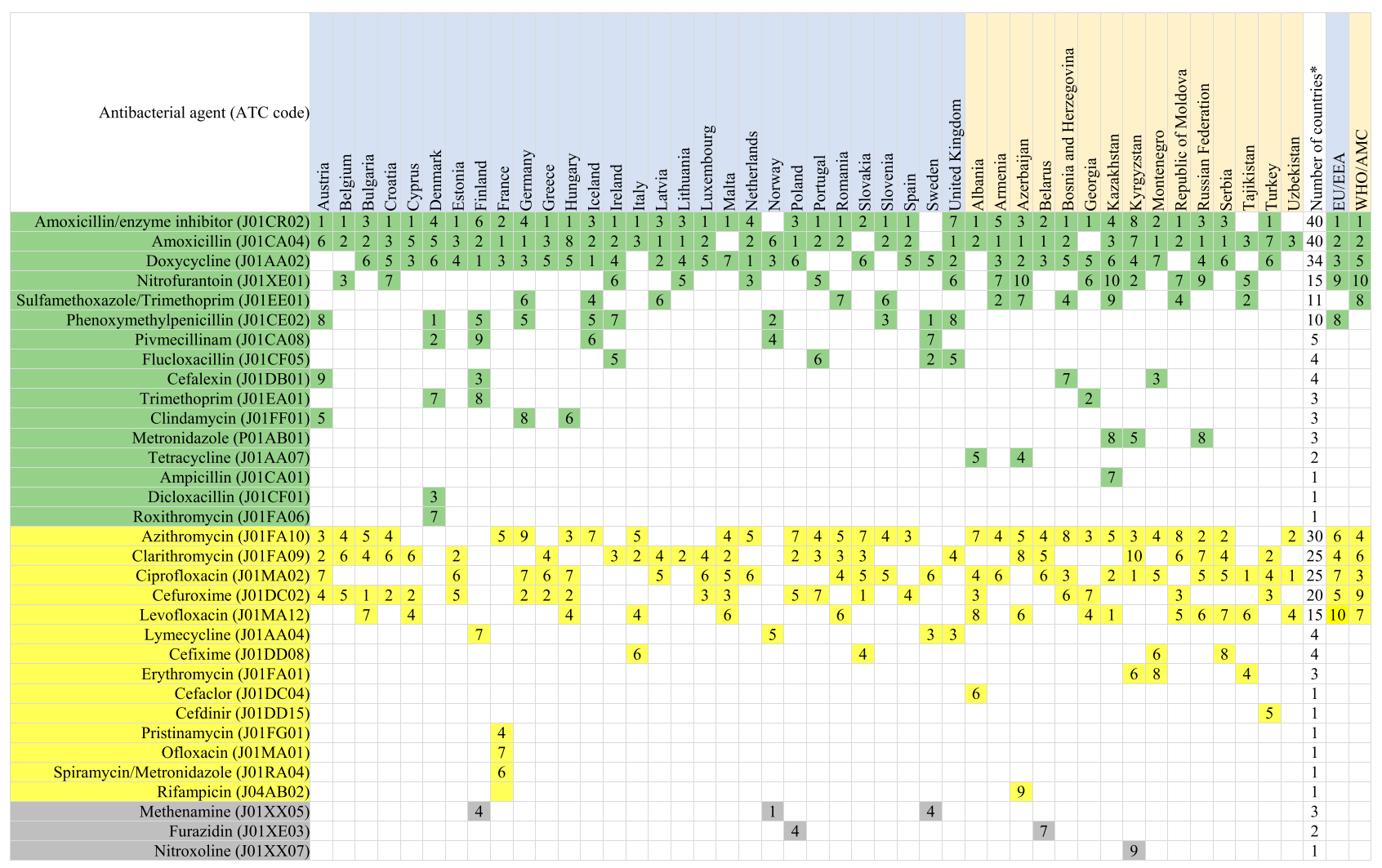

Agents included in this analysis: antibacterials for systemic use (J01), neomycin (A07AA01), streptomycin (A07AA04), polymyxin B (A07AA05), kanamycin (A07AA08), vancomycin (A07AA09), colistin (A07AA10), rifamixin (A07AA11), rifampicin (J04AB02), rifamycin (J04AB03), rifabutin (J04AB04), metronidazole (P01AB01).

The table is sorted according to the number of countries which included the antimicrobial in the DU75\%, considering Access (green panel), Watch (yellow panel) and unclassified agents (gray panel) separately (World Health Organization 2019).

*Numbers of countries which have this agent in DU75\%.

EU/EEA population-weighted mean for countries of ESAC-Net.

WHO/AMC population-weighted mean for countries of the WHO Europe AMC Network.

The numbers shown in the table refer to the frequency of use, e.g. 1 = most often consumed antimicrobial.

infectious diseases and AMR, as well as other determinants of AMC including differences in patient expectations, vary between countries (Fletcher-Lartey et al., 2016; Sirota et al., 2017; and; Ritchie et al., 2019). Several disparities reflect the fact that certain antibiotics, for example, phenoxymethylpenicillin, flucloxacillin and pivmecillinam, are not registered in some countries. Other disparities, such as more reliance on parenteral products and greater use of quinolones in WHO Europe AMC Network than ESAC-Net countries, are more likely to reflect prescribing practices and cultural preferences and are potential targets for interventions and behavior change.

High levels of consumption of Watch agents are an obvious target for interventions including review of clinical guidelines and prescribing algorithms. Low levels of consumption of Reserve agents in this study reflect the analysis of data on total consumption combining community and hospital sectors and different consumption patterns would be expected in analyses of hospital data alone. While some classes of agents will be used almost exclusively in the hospital setting, on average, $90 \%$ of overall national antibiotic consumption across European countries is community consumption. Disaggregation of data to hospital and community sectors was not possible in most WHO Europe AMC Network countries; however, this is an important future development as countries strengthen and enhance their surveillance capacity and recognize the value of disaggregated data to inform stewardship activities in the community and hospital sectors.

Fourteen ESAC-Net countries met WHO's suggested national target of $60 \%$ of total consumption of antibacterials being derived from the Access list in each of the five years analyzed. This suggests that more ambitious targets may be warranted in highincome countries that already have implemented comprehensive monitoring and intervention programmes to address AMR. In contrast, only one country in the WHO Europe AMC Network achieved this target in each of the five years. The findings in the high-income countries compare well with Canada where there was evidence of increasing relative consumption of Access agents between 2014 and 2018, reaching $67.5 \%$ of total consumption in 2018 (Public Health Agency of Canada, 2020).

Despite the expansion of the AWaRe classification in 2019 to include 180 antibacterials used globally (World Health 
TABLE 4 | Antibacterials at substance level (5th ATC group level) that compose the DU75\%, parenteral use, 2018.

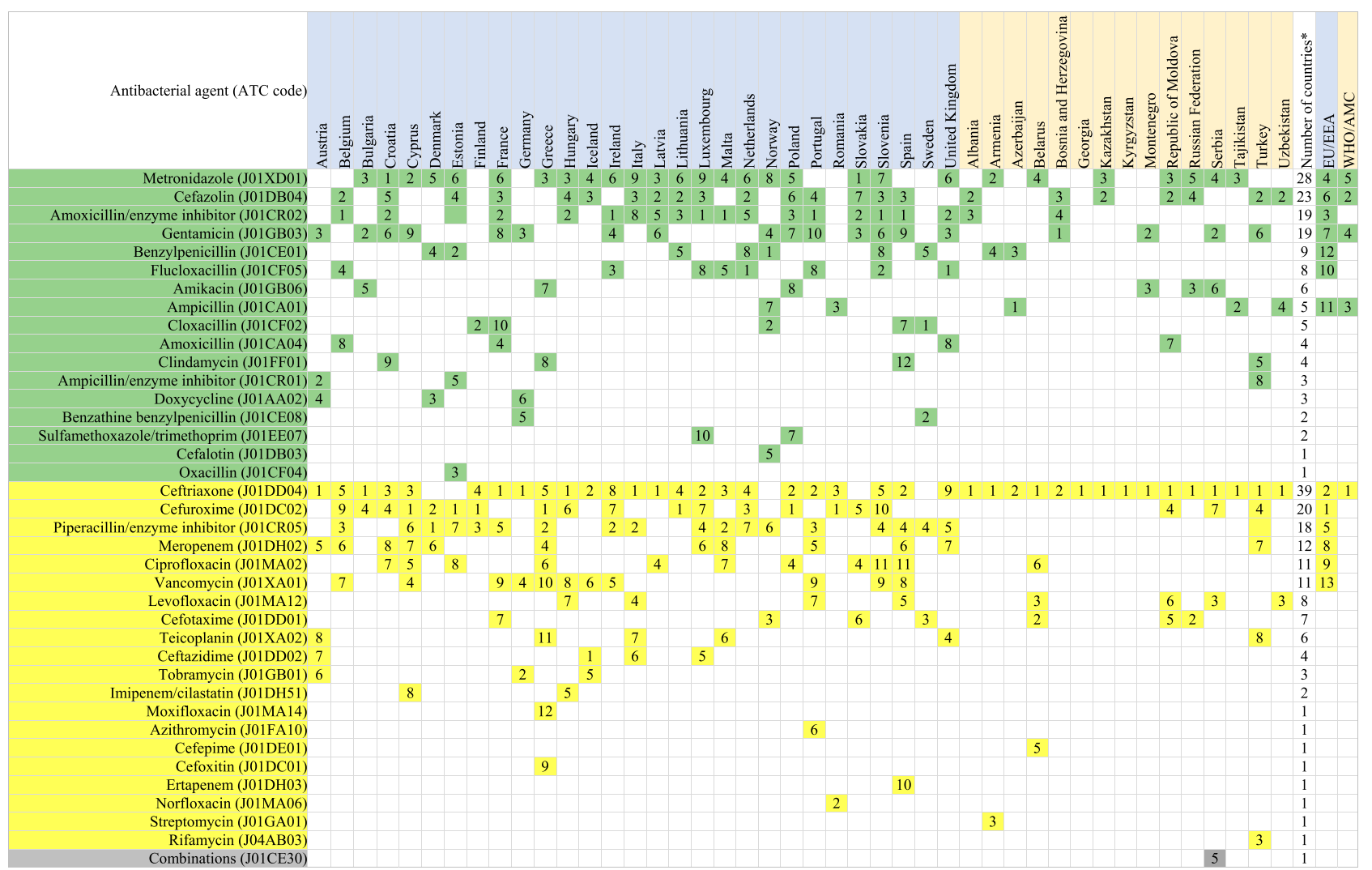

Agents included in this analysis: antibacterials for systemic use (J01), neomycin (A07AA01), streptomycin (A07AA04), polymyxin B (A07AA05), kanamycin (A07AA08), vancomycin (A07AA09), colistin (AO7AA10), rifamixin (A07AA11), rifampicin (J04AB02), rifamycin (J04AB03), rifabutin (J04AB04), metronidazole (P01AB01).

The table is sorted according to the number of countries which included the antimicrobial in the DU75\%, considering Access (green panel), Watch (yellow panel) and unclassified agents (gray panel) separately (World Health Organization 2019).

*Numbers of countries which have this agent in DU75\%.

EU/EEA population-weighted mean for countries of ESAC-Net.

WHO/AMC population-weighted mean for countries of the WHO Europe AMC Network.

The numbers shown in the table refer to the frequency of use, e.g. $1=$ most often consumed antimicrobial.

Organization, 2019), three oral agents, methenamine (J01XX05), furazidin (J01XE03) and nitroxoline (J01XX07), all used for the prophylaxis or treatment of urinary tract infections, yet remain unclassified, but appear in the DU75\% for four ESAC-Net countries and two WHO Europe AMC Network countries. There is an opportunity for WHO in the future to address the limitations in the current list and to expand the AWaRe classification to include antimicrobials that are commonly used in some countries. Unclassifed agents constituted $24.1 \%$ of total consumption in Norway in 2018, mostly accounted for by methenamine, which is commonly used for prophylaxis of urinary tract infections in elderly women and is not considered to be an AMR-inducing agent (Alberg et al., 2017). Our estimates of the consumption of unclassified agents differ from those reported by Klein et al., (2020). These authors used expert consultations to classify 54 of 233 antibiotics included in the sales data of the IQVIA database that are currently not included in the AWaRe classification, leaving only three agents in their unclassified group.
As noted in other studies, the number of antimicrobials constituting the DU75\% by substance was small (Zarb et al., 2011) with a median of seven and eight different oral agents in ESAC-Net and WHO Europe AMC Network countries, respectively. Linking the DU75\% analysis to the AWaRe classification adds further value, illustrating differences in choices of agents between countries and networks, their ranking by consumption rates and identifying potential targets for interventions to improve practices.

The limitations of some of the data have implications for interpretation of results. Only medicines with an assigned ATC code and DDD are included in the analyses. Where there are medicines without codes consumed by the population, estimates of DDD per 1000 inhabitants per day will be underestimated. While import records have limitations, they will include over-thecounter supply of antibacterials without prescription that occurs in some countries. Differences in data sources can limit some comparisons. Supply cycles may influence consumption estimates in some settings while customs records and data from local manufacturers are a crude proxy for consumption. 
However, in the absence of more robust data, using these sources allow countries to start the important task of monitoring antibacterial consumption as part of national efforts to address AMR. The ATC/DDD methodology provides a common technical basis for surveillance of antimicrobial consumption. Where sources remain the same, it is possible to discern trends more reliably in volumes and patterns of consumption over time.

Despite similar estimates of total consumption of antibacterials for systemic use (ATC J01) in the Netherlands and in Azerbaijan, 9.7 and 8.9 DDD per 1000 inhabitants per day, respectively, the situation in the two countries is different. Trend analyses demonstrate statistically significant reductions in total consumption in the Netherlands but increasing total consumption in Azerbaijan during 2014-2018. The low starting baseline of consumption estimates for Azerbaijan in 2014 and variability over the study period could suggest poor access to antibiotics, incomplete capture of import and local manufacturing information, the impact of medicines import cycles, or combinations of these factors. Nevertheless, this increase in total consumption over time is consistent with the findings of other studies linking increasing consumption in low- and middle-income countries to growth in gross domestic product per capita (Klein et al., 2018), and the quality of governance in the pharmaceutical sector including regulatory practices and enforcement of regulations (Rönnerstrand and Lapuente, 2017). Malik and Bhattacharyya (2019) modeled complex associations between socio-economic growth, ecology of infectious disease and antibiotic misuse, particularly through selfmedication, suggesting there are synergistic interactions of these components feeding back on each other and contributing to AMR.

Similar to the large variations in antibiotic consumption between countries described by this study and other global analyses (Klein et al., 2020), considerable differences in the proportion of AMR in key pathogens have been reported for both EU/EEA countries (European Centre for Disease Prevention and Control, 2019b) and non-EU/EEA European countries (World Health Organization Regional Office for Europe, 2018). Associations between national antimicrobial consumption rates and national AMR levels, in both the hospital and community sector, have been reported for EU/EEA countries (European Centre for Disease Prevention and Control and European Food Safety Authority and European Medicines Agency, 2017b), highlighting the importance of addressing antibiotic consumption as part of national efforts towards reducing the burden of AMR in Europe (Wojkowska-Mach et al., 2018). Furthermore, disaggregation of data to community and hospital sectors facilitates monitoring using sector-specific metrics for quantifying antibiotic use and assessing the quality of prescribing (Coenen et al., 2007; de Bie et al., 2016; Stanic Benic et al., 2018). Hospital antimicrobial stewardship programmes that generally focus on changes to antimicrobial use practices have also demonstrated their value in delivering clinical and economic benefits, with reductions in length of stay a key driver of cost savings (Nathwani et al., 2019). Community interventions can be developed, building on existing evidence that communication skills training and changing patient expectations to receive antibiotics can lead to significant reductions in antibiotic prescriptions for viral upper respiratory tract infections (Ritchie et al., 2019; Strumann et al., 2020).
In conclusion, the development and implementation of effective national policies to deal with AMR vary across countries in both ESAC-Net and the WHO Europe AMC Network. Reliable data are needed to describe patterns of AMC and to monitor the evolution of AMR. Standardized methods of data collection and analysis and the application of common metrics and indicators facilitate benchmarking across settings, countries and regions. The quantitative estimates presented should be considered a starting point for further studies to understand better the use of these medicines in clinical practice this will require further quantitative and qualitative studies in primary care and hospital sectors at the country level.

The longer history and experience of ESAC-Net provides an important platform from which to build capacity for monitoring and evaluation in the WHO Europe AMC Network. Subsequent cross-national comparisons, especially including quality measures, can stimulate national and regional discussions and promote activities and interventions to address problem practices. Timely data are important if they are to be used to guide policy developments at the national level. This study included data for 2018 and captured information on patterns of antibiotic consumption in countries in Eastern Europe and Central Asia that are currently not well represented in global sales databases such as IQVIA (Klein et al., 2020).

Several factors support increased engagement and information exchange between ESAC-Net and the WHO Europe AMC Network. Beyond geographic proximity, several members of the WHO Europe AMC Network are candidate countries for accession to the EU (European Commission, 2020b). In advance of membership, these countries must revise their national legislation to be able to apply the EU's acquis, the body of common rights and obligations that are binding on all EU Member States. This will promote harmonization of procedures for registration of pharmaceutical products including antibiotics across Europe. Furthermore, strategic partnerships are a cornerstone of the 2020-2025 WHO European Programme of Work (World Health Organization Regional Office for Europe 2020c), and this will facilitate building on complementary work already being undertaken by agencies aligned with the European Commission and WHO Europe. Overall, we believe that this study illustrates the value of harmonized approaches to data collection and analysis of antibiotic consumption data that can underpin Europe-wide strategies to address AMR. In parallel with joint reporting of AMR data from the European Antimicrobial Resistance Surveillance Network (EARS-Net) and the WHO Europe Central Asian and European Surveillance of Antimicrobial Resistance (CAESAR) network, we plan further reporting on joint ESAC-Net and WHO Europe AMC surveillance in the future.

\section{Group Authors}

Authors contributing to the ESAC-Net and WHO Europe AMC Network study groups are shown below.

\section{DATA AVAILABILITY STATEMENT}

The data analyzed in this study are subject to the following licenses/restrictions: Data from ESAC-Net are publicly 


\section{Authors contributing to the ESAC-Net study group:}

\begin{tabular}{|c|c|c|}
\hline Austria & Reinhild Strauss & Federal Ministry for Social Affairs, Health, Care and Consumer Protection \\
\hline Belgium & Eline Vandael & Sciensano \\
\hline Bulgaria & Ivan N. Ivanov & National Center of Infectious and Parasitic Diseases \\
\hline Croatia & Marina Payerl-Pal & The Interdisciplinary Section for Antibiotic Resistance Control, Ministry of Health \\
\hline Cyprus & Isavella Kyriakidou & Pharmaceutical Services, Ministry of Health \\
\hline Denmark & Majda Attauabi & Statens Serum Institut \\
\hline Estonia & Elviira Linask & Estonian State Agency of Medicines \\
\hline France & $\begin{array}{l}\text { Karima } \\
\text { Hider - Mlynarz }\end{array}$ & $\begin{array}{l}\text { EPI-PHARE, epidemiology of health products (French National Agency for the Safety of Medicines and Health Products, } \\
\text { and French National Health Insurance) }\end{array}$ \\
\hline Germany & Birgitta Schweickert & $\begin{array}{l}\text { Robert Koch Institute, Department: Healthcare-associated Infections, Surveillance of Antimicrobial Resistance and } \\
\text { Consumption, Berlin }\end{array}$ \\
\hline Hungary & Ria Benkö & $\begin{array}{l}\text { University of Szeged, Department of Clinical Pharmacy, Albert Szent Györgyi Health Center, Central Pharmacy and } \\
\text { Department of Emergency Medicine }\end{array}$ \\
\hline Iceland & Guðrún Aspelund & Center for Health Security and Communicable Disease Control, Directorate of Health, Reykjavik \\
\hline Ireland & Karen Burns & Health Protection Surveillance Center, Dublin \\
\hline Italy & Filomena Fortinguerra & Italian Medicines Agency (AIFA), Rome \\
\hline Latvia & leva Rutkovska & Centre for Disease Prevention and Control, Department of Infectious Disease Surveillance and Immunization, Riga \\
\hline Luxembourg & Martine Trauffler & Division of Pharmacy and Medicines, Directorate of Health \\
\hline Malta & Peter Zarb & National Antibiotic Committee \\
\hline Netherlands & Stephanie Natsch & Department of Pharmacy, Radboud university medical center, Nijmegen \\
\hline Norway & Hege Salvesen Blix & Norwegian Institute of Public Health \\
\hline Poland & $\begin{array}{l}\text { Anna Olczak- } \\
\text { Pieńkowska }\end{array}$ & National Medicines Institute, Department of Epidemiology and Clinical Microbiology \\
\hline Portugal & Ana Silva & INFARMED - National Authority of Medicines and Health Products, I.P. \\
\hline Romania & lonel losif & National Institute of Public Health, National Center for Disease Prevention and Control, Bucharest \\
\hline Slovakia & Tomáš Tesař & Department of Organization and Management in Pharmacy, Pharmaceutical Faculty, Comenius University in Bratislava \\
\hline Slovenia & Milan Cižman & University Medical Center, Department of Infectious Diseases, Ljubljana \\
\hline Spain & Mayte Alonso & National Agency for Drugs and Medical Devices \\
\hline Sweden & Vendela Bergfeldt & Public Health Agency of Sweden \\
\hline United Kingdom & Susan Hopkins & National Infection Service, Public Health England \\
\hline
\end{tabular}

Authors contributing to the WHO Europe AMC Network study group:

\begin{tabular}{|c|c|c|}
\hline Albania & Narvina Sinani & National Agency for Drugs and Medical Devices \\
\hline Armenia & Lilit Ghazaryan & Scientific Center of Drug and Medical Technology Expertize of Ministry of Health \\
\hline Azerbaijan & Fikriyya Ibrahimli & Analytical Expertize Center of Ministry of Health \\
\hline $\begin{array}{l}\text { Bosnia and } \\
\text { Herzegovina }\end{array}$ & Tijana Spasojević & $\begin{array}{l}\text { Sector for Providing Information on Drugs and Medical Products in Agency for Medicinal Products and Medical Devices of } \\
\text { Bosnia and Herzegovina }\end{array}$ \\
\hline Belarus & Halina Pyshnik & Department of Organization of Medicines Supply, Ministry of Health \\
\hline Georgia & Marine Baidauri & Health Policy Division of Policy Department Ministry of IDPs, Labor, Health and Social Affairs of Georgia \\
\hline Kazakhstan & Larissa Makalkina & $\begin{array}{l}\text { Department of Clinical Pharmacology, Astana Medical University Republican Public Union "Professional Association of } \\
\text { Clinical Pharmacologists and Pharmacists" }\end{array}$ \\
\hline Kyrgyzstan & Aizhan Tabaldyeva & Unit on Specialized Expertize of Medicines of Department of Drug Provision and Medical Devices, Ministry of Health \\
\hline Republic of Moldova & Angela Carp & P.I. Coordination, Implementation and Monitoring Unit of the Health System Projects \\
\hline Montenegro & Lidija Čizmović & $\begin{array}{l}\text { Department for Establishing Maximum Prices and Monitoring Consumption of Medicines, Agency for Medicines and } \\
\text { Medical Devices }\end{array}$ \\
\hline Russian Federation & Svetlana Rachina & Internal Medicine Department №2, I.M. Sechenov First Moscow State Medical University, Moscow, Russian Federation \\
\hline Serbia & Milica Bajčetić & Department of Pharmacology, Clinical Pharmacology and Toxicology, Faculty of Medicine, University of Belgrade, Serbia \\
\hline Tajikistan & Nargis Kalandarova & $\begin{array}{l}\text { Department of Conformity Assessment of Medicines of the State Unitary Enterprise for Examination and Testing } \\
\text { Pharmaceutical and Medical Products of the State Service Health and Social Protection of Population Supervision }\end{array}$ \\
\hline Turkey & Mesil Aksoy & Department of Rational Use of Medicines. Turkish Medicines and Medical Devices Agency, Ministry of Health of Turkey \\
\hline Uzbekistan & Mukhabbat Ibragimova & $\begin{array}{l}\text { Agency on Development of the Pharmaceutical Industry under the Ministry of Health of the Republic of Uzbekistan. Head of } \\
\text { Information and Analytics Department }\end{array}$ \\
\hline
\end{tabular}

accessible from the ESAC-Net interactive database and under some circumstances after submission of a request for access to data to The European Surveillance System. The European Surveillance System database allows for correction and reuploading of historical data by the reporting countries. Therefore, the results presented here may differ from the most recent available data at the public interactive ESAC-Net database. No further data are available for the WHO Europe AMC Network. Requests to access ESAC-Net datasets should be directed to https://www.ecdc.europa.eu/en/publicationsdata/european-surveillance-system-tessy.

\section{AUTHOR CONTRIBUTIONS}

JR, VV-P, KI, KW developed the concept and designed the study. Acquisition and analysis of the data: all authors. Interpretation of results of the study: all authors. Writing of 
the first draft: JR, VV-P, KI, LDH, KW. All authors critically reviewed and edited the final manuscript and agreed to submission of the manuscript.

\section{FUNDING}

For ESAC-Net, no specific funding was allocated for this study. The Netherlands Ministry of Health, Welfare, and Sport, and the German Collaboration Programme provide funding for the

\section{REFERENCES}

Alberg, T., Holen, Ø., Blix, H. S., Lindbæk, M., Bentele, H., and Eriksen, H. M. (2017). Antibiotikabruk og infeksjoner i sykehjem. Tidsskriftet 137, 357-361. doi:10.4045/tidsskr.16.0621

Cassini, A., Högberg, L. D., Plachouras, D., Quattrocchi, A., Hoxha, A., Simonsen, G. S., et al. (2019). Attributable deaths and disability-adjusted life-years caused by infections with antibiotic-resistant bacteria in the EU and the European Economic Area in 2015: a population-level modelling analysis. Lancet Infect. Dis. 19, 56-66. doi:10.1016/s1473-3099(19)30004-0

Coenen, S., Ferech, M., Haaijer-Ruskamp, F. M., Butler, C. C., Vander Stichele, R. H., Verheij, T. J. M., et al. (2007). European Surveillance of Antimicrobial Consumption (ESAC): quality indicators for outpatient antibiotic use in Europe. Qual. Saf. Health Care 16, 440-445. doi:10. 1136/qshc.2006.021121

de Bie, S., Kaguelidou, F., Verhamme, K. M. C., De Ridder, M., Picelli, G., Straus, S. M. J. M., et al. (2016). Using prescription patterns in primary care to derive new quality indicators for childhood community antibiotic prescribing. Pediatr. Infect. Dis. J. 35, 1317-1323. doi:10.1097/inf. 0000000000001324

European Centre for Disease Prevention and Control (2019a). Antimicrobial consumption. In ECDC. Annual epidemiological report 2018. Stockholm, Sweden: ECDC. Available at: https://www.ecdc.europa.eu/sites/default/files/ documents/Antimicrobial-consumption-EU-EEA.pdf (Accessed July 8, 2020).

European Centre for Disease Prevention and Control (2020). European surveillance of antimicrobial consumption network (ESAC-Net). In European Centre for disease prevention and Control. Stockholm, Sweden: ECDC. Available at: https://www.ecdc.europa.eu/en/about-us/partnerships-and-networks/disease-andlaboratory-networks/esac-net (Accessed July 8, 2020).

European Centre for Disease Prevention and Control (2019b). Surveillance of antimicrobial resistance in Europe 2018. Stockholm, Sweden: ECDC. Available at: https://www.ecdc.europa.eu/sites/default/files/documents/surveillanceantimicrobial-resistance-Europe-2018.pdf (Accessed July 8, 2020).

European Centre for Disease Prevention and Control; European Food Safety Authority and European Medicines Agency (2017a). ECDC, EFSA and EMA Joint Scientific Opinion on a list of outcome indicators as regards surveillance of antimicrobial resistance and antimicrobial consumption in humans and food-producing animals. Available at: https://www.efsa.europa. eu/en/efsajournal/pub/5017 (Accessed July 8, 2020).

European Centre for Disease Prevention and Control; European Food Safety Authority and European Medicines Agency (2017b). ECDC/EFSA/EMA second joint report on the integrated analysis of the consumption of antimicrobial agents and occurrence of antimicrobial resistance in bacteria from humans and food-producing animals - joint Interagency Antimicrobial Consumption and Resistance Analysis (JIACRA) Report. Available at: https:// www.ecdc.europa.eu/en/publications-data/ecdcefsaema-second-joint-reportintegrated-analysis-consumption-antimicrobial (Accessed July 8, 2020).

European Commission (2017). A European one health action plan against antimicrobial resistance (AMR). Available at: https:/lec.europa.eu/health/ antimicrobial-resistance/eu-action-on-antimicrobial-resistance_en (Accessed July 1,2020 ).

European Commission (2020a). Eurostat [internet]. Brussels, Belgium: Eurostat. Available at: http://ec.europa.eu/eurostat (Accessed July 8, 2020).
WHO Europe AMC Network, but had no role in the study design, data collection, data analysis, data interpretation, or writing of the manuscript.

\section{SUPPLEMENTARY MATERIAL}

The Supplementary Material for this article can be found online at: https://www.frontiersin.org/articles/10.3389/fphar.2021.639207/ full\#supplementary-material

European Commission (2020b). European neighbourhood policy and enlargement negotiations. Available at: https://ec.europa.eu/neighbourhood-enlargement/ countries/check-current-status_en (Accessed July 23, 2020).

Fletcher-Lartey, S., Yee, M., Gaarslev, C., and Khan, R. (2016). Why do general practitioners prescribe antibiotics for upper respiratory tract infections to meet patient expectations: a mixed methods study. BMJ Open 6, e012244. doi:10. 1136/bmjopen-2016-012244

Hofer, U. (2019). The cost of antimicrobial resistance. Nat. Rev. Microbiol. 17, 3. doi:10.1038/s41579-018-0125-x

Hsia, Y., Sharland, M., Jackson, C., Wong, I. C. K., Magrini, N., and Bielicki, J. A. (2019a). Consumption of oral antibiotic formulations for young children according to the WHO Access, Watch, Reserve (AWaRe) antibiotic groups: an analysis of sales data from 70 middle-income and high-income countries. Lancet Infect. Dis. 19, 67-75. doi:10.1016/S1473-3099(18)30547-4

Hsia, Y., Lee, B. R., Versporten, A., Yang, Y., Bielicki, J., Jackson, C., et al. (2019b). Use of the WHO Access, Watch, and Reserve classification to define patterns of hospital antibiotic use (AWaRe): an analysis of paediatric survey data from 56 countries. Lancet Glob. Health 7, e861-e871. doi:10.1016/S2214109X(19)30071-3

Klein, E. Y., Milkowska-Shibata, M., Tseng, K. K., Sharland, M., Gandra, S., Pulcini, C., et al. (2020). Assessment of WHO antibiotic consumption and access targets in 76 countries, 2000-15: an analysis of pharmaceutical sales data. Lancet Infect. Dis. 21 (1), 107-115. doi:10.1016/S1473-3099(20)30332-7

Klein, E. Y., Van Boeckel, T. P., Martinez, E. M., Pant, S., Gandra, S., Levin, S. A., et al. (2018). Global increase and geographic convergence in antibiotic consumption between 2000 and 2015. Proc. Natl. Acad. Sci. USA 115, E3463-E3470. doi:10.1073/pnas.1717295115

Laxminarayan, R., Van Boeckel, T., Frost, I., Kariuki, S., Khan, E. A., Limmathurotsakul, D., et al. (2020). The Lancet Infectious Diseases Commission on antimicrobial resistance: 6 years later. Lancet Infect. Dis. 20, e51-e60. doi:10.1016/s1473-3099(20)30003-7

Malik, B., and Bhattacharyya, S. (2019). Antibiotic drug-resistance as a complex system driven by socio-economic growth and antibiotic misuse. Sci. Rep. 9, 9788. doi:10.1038/s41598-019-50846-1

Malik, F., and Figueras, A. (2019). Analysis of the antimicrobial market in Pakistan: is it really necessary such a vast offering of "Watch" antimicrobials? Antibiotics 8, 189. doi:10.3390/antibiotics 8040189

McGettigan, P., Roderick, P., Kadam, A., and Pollock, A. M. (2017). Access, Watch, and Reserve antibiotics in India: challenges for WHO stewardship. Lancet Glob. Health 5, e1075-76. doi:10.1016/s2214-109x(17)30365-0

Nathwani, D., Varghese, D., Stephens, J., Ansari, W., Martin, S., and Charbonneau, C. (2019). Value of hospital antimicrobial stewardship programs [ASPs]: a systematic review. Antimicrob. Resist. Infect. Control. 8, 35. doi:10.1186/s13756019-0471-0

O’Neill, J. (2016). Tackling drug-resistance infections globally: final report and recommendations of the review on antimicrobial resistance. Available at: https://amr-review.org/ (Accessed August 17, 2020).

Public Health Agency of Canada (2020). Canadian antimicrobial resistance surveillance system report. Available at: https:/www.canada.ca/content/dam/ hc-sc/documents/services/drugs-health-products/canadian-antimicrobialresistance-surveillance-system-2020-report/CARSS-2020-report-2020-eng.pdf (Accessed July 23, 2020).

Ritchie, S. R., Rakhmanova, L., Out-O’Reilly, E., Reay, S., Thomas, M. G., and Sajtos, L. (2019). The use of a poster to reduce expectations to receive antibiotics 
for a common cold. Eur. J. Clin. Microbiol. Infect. Dis. 38, 1463-1469. doi:10. 1007/s10096-019-03572-5

Robertson, J., Iwamoto, K., Hoxha, I., Ghazaryan, L., Abilova, V., Cvijanovic, A., et al. (2019). Antimicrobial medicines consumption in Eastern Europe and Central Asia - an updated cross-national study and assessment of quantitative metrics for policy action. Front. Pharmacol. 9, 1156. doi:10.3389/fphar.2018. 01156

Rönnerstrand, B., and Lapuente, V. (2017). Corruption and use of antibiotics in regions of Europe. Health Policy 121, 250-256. doi:10.1016/j.healthpol.2016. 12.010

Safrany, N., and Monnet, D. L. (2012). Antibiotics obtained without a prescription in Europe. Lancet Infect. Dis. 12, 182-183. doi:10.1016/S1473-3099(12)70017-8

Schweickert, B., Feig, M., Schneider, M., Willrich, N., Behnke, M., Peña Diaz, L. A., et al. (2018). Antibiotic consumption in Germany: first data of a newly implemented web-based tool for local and national surveillance. J. Antimicrob. Chemother. 73, 3505-3515. doi:10.1093/jac/dky345

Sharland, M., Gandra, S., Huttner, B., Moja, L., Pulcini, C., Zeng, M., et al. (2019). Encouraging AWaRe-ness and discouraging inappropriate antibiotic use-the new 2019 Essential Medicines List becomes a global antibiotic stewardship tool. Lancet Infect. Dis. 19, 1278-1280. doi:10.1016/S1473-3099(19)30532-8

Sirota, M., Round, T., Samaranayaka, S., and Kostopoulou, O. (2017). Expectations for antibiotics increase their prescribing: causal evidence about localized impact. Health Psychol. 36, 402-409. doi:10.1037/hea0000456

Stanic Benic, M., Milanic, R., Monnier, A. A., Gyssens, I. C., Adriaenssens, N., Versporten, A., et al. (2018). Metrics for quantifying antibiotic use in the hospital setting: results from a systematic review and international multidisciplinary consensus procedure. J. Antimicrob. Chemother. 73 (Suppl. 1_6), vi50-vi58. doi:10.1093/jac/dky118

Strumann, C., Steinhaeuser, J., Emcke, T., Sönnichsen, A., and Goetz, K. (2020). Communication training and the prescribing pattern of antibiotic prescription in primary health care. PloS one 15-e0233345. doi:10.1371/journal.pone.0233345

Sulis, G., Adam, P., Nafade, V., Gore, G., Daniels, B., Daftary, A., et al. (2020). Antibiotic prescription practices in primary care in low- and middle-income countries: a systematic review and meta-analysis. Plos Med. 17 (6), e1003139. doi:10.1371/journal.pmed.1003139

The World Bank (2020). DataBank: population estimates and projections. Available at: https://databank.worldbank.org/source/population-estimatesand-projections (Accessed July 23, 2020).

Versporten, A., Bolokhovets, G., Ghazaryan, L., Abilova, V., Pyshnik, G., Spasojevic, T., et al. (2014). On behalf of the WHO/Europe-ESAC Project GroupAntibiotic use in eastern Europe: a cross-national database study in coordination with the WHO Regional Office for Europe. Lancet Infect. Dis. 14, 381-387. doi:10.1016/s1473-3099(14)70071-4

WHO Collaborating Centre for Drug Statistics Methodology (2020). Anatomical Therapeutic Chemical (ATC) classification system: guidelines for ATC classification and DDD assignment 2020. Oslo, Norway: WHO Collaborating Centre for Drug Statistics Methodology. Available at: https://www.whocc.no/atc_ddd_index_and_guidelines/guidelines/ (Accessed July 8,2020 ).

WHO Collaborating Centre for Drug Statistics Methodology (2018). DDD: definition and general considerations. Oslo, Norway: WHO Collaborating Centre for Drug Statistics Methodology. Available at: https://www.whocc. no/ddd/definition_and_general_considera/ (Accessed July 1, 2020).

Wojkowska-Mach, J., Godman, B., Glassman, A., Kurdi, A., Pilc, A., Rozanska, A., et al. (2018). Antibiotic consumption and antimicrobial resistance in Poland; findings and implications. Antimicrob. Resist. Infect. Control. 7, 136. doi:10. 1186/s13756-018-0428-8

World Health Organization (2020). Adopt AWaRe: handle antibiotics with care. Available at: https://adoptaware.org/ (Accessed July 8, 2020).
World Health Organization (2019). AWaRe classification database. Available at: https://www.who.int/medicines/news/2019/WHO_releases2019AWaRe_classification_ antibiotics/en/ (Accessed July 1, 2020).

World Health Organization (2018). WHO report on surveillance of antibiotic consumption: 2016-2018 early implementation. Geneva, Switzerland: World Health Organization. . 2018. Licence: CC BY-NC-SA 3.0 IGO. Available at: https://www.who.int/medicines/areas/rational_use/oms-amr-amc-report-2016-2018/ en/(Accessed July 1, 2020).

World Health Organization (2015). Global action plan on antimicrobial resistance. Available at: https:/www.who.int/antimicrobial-resistance/publications/ global-action-plan/en/ (Accessed July 1, 2020).

World Health Organization Regional Office for Europe (2020a). Antimicrobials. Available at: https://www.euro.who.int/en/health-topics/Health-systems/ health-technologies-and-medicines/policy-areas/antimicrobials (Accessed July 8,2020 ).

World Health Organization Regional Office for Europe (2020b). WHO Regional Office for Europe Antimicrobial Medicines Consumption (AMC) Network. AMC data 2011-2017. Available at: https://www.euro.who.int/en/publications/ abstracts/who-regional-office-for-europe-antimicrobial-medicines-consumptionamc-network.-amc-data-20112017-2020 (Accessed July 8, 2020).

World Health Organization Regional Office for Europe (2020c). European programme of work, 2020-2025 - 'united action for better health in Europe'. Available at: https://www.euro.who.int/en/health-topics/healthpolicy/european-programme-of-work (Accessed September 24, 2020).

World Health Organization Regional Office for Europe (2018). Central Asian and European Surveillance of Antimicrobial Resistance. Annual Report 2018. Copenhagen, Denmark: WHO Regional Office for Europe. Available at: https://www.euro.who.int/en/health-topics/disease-prevention/antimicrobialresistance/publications/2018/central-asian-and-eastern-european-surveillance-ofantimicrobial-resistance-annual-report-2018-2018 (Accessed July 8, 2020).

World Health Organization Regional Office for Europe (2011). EUR/RC61/14 European strategic action plan on antibiotic resistance. Available at: https://www.euro.who. int/en/about-us/governance/regional-committee-for-europe/past-sessions/ sixty-first-session/documentation/working-documents/wd14-european-strategicaction-plan-on-antibiotic-resistance (Accessed July 1, 2020).

Zarb, P., Ansari, F., Muller, A., Vankerckhoven, V., Davey, P. G., and Goossens, H. (2011). Drug utilization 75\% (DU75\%) in 17 European hospitals (2000-2005): results from the ESAC-2 hospital care sub project. Curr. Clin. Pharmacol. 6, 62-70. doi:10.2174/157488411794941322

Disclaimer: Some of the authors are staff members of the World Health Organization. The authors alone are responsible for the views expressed in this publication and they do not necessarily represent the views, decisions or policies of the World Health Organization.

Conflict of Interest: The authors declare that the research was conducted in the absence of any commercial or financial relationships that could be construed as a potential conflict of interest.

Copyright $\odot$ World Health Organization 2021. Licensee Frontiers Media SA. This is an open access article distributed under the terms of the Creative Commons Attribution IGO License (http://creativecommons.org/licenses/by/3.0/igo/legalcode), which permits unrestricted use, adaptation (including derivative works), distribution, and reproduction in any medium, provided the original work is properly cited. In any reproduction or adaptation of this article there should not be any suggestion that WHO or this article endorse any specific organisation or products. The use of the WHO logo is not permitted. This notice should be preserved along with the article's original URL. 